\title{
Adverse Vascular Effects of Homocysteine Are Modulated by Endothelium-derived Relaxing Factor and Related Oxides of Nitrogen
}

\author{
Jonathan S. Stamler, * John A. Osborne, * Omar Jaraki, * Leroy E. Rabbani, * \\ Mark Mullins, ${ }^{*}$ David Singel, ${ }^{\star}$ and Joseph Loscalzo* \\ * Department of Medicine, Cardiovascular Division, Brigham and Women's Hospital, Brockton/West Roxbury \\ Veterans Administration Medical Center, Harvard Medical School, Boston, Massachusetts 02115; \\ and ${ }^{\ddagger}$ Department of Chemistry, Harvard University, Cambridge, Massachusetts 02138
}

\begin{abstract}
Elevated levels of homocysteine are associated with an increased risk of atherosclerosis and thrombosis. The reactivity of the sulfhydryl group of homocysteine has been implicated in molecular mechanisms underlying this increased risk. There is also increasingly compelling evidence that thiols react in the presence of nitric oxide (NO) and endothelium-derived relaxing factor (EDRF) to form $S$-nitrosothiols, compounds with potent vasodilatory and antiplatelet effects. We, therefore, hypothesized that S-nitrosation of homocysteine would confer these beneficial bioactivities to the thiol, and at the same time attenuate its pathogenicity. We found that prolonged $(>3 \mathrm{~h})$ exposure of endothelial cells to homocysteine results in impaired EDRF responses. By contrast, brief ( $15 \mathrm{~min}$ ) exposure of endothelial cells, stimulated to secrete EDRF, to homocysteine results in the formation of $\boldsymbol{S}$-NO-homocysteine, a potent antiplatelet agent and vasodilator. In contrast to homocysteine, $S$-NO-homocysteine does not support $\mathrm{H}_{2} \mathrm{O}_{2}$ generation and does not undergo conversion to homocysteine thiolactone, reaction products believed to contribute to endothelial toxicity. These results suggest that the normal endothelium modulates the potential, adverse effects of homocysteine by releasing EDRF and forming the adduct $S$-NO-homocysteine. The adverse vascular properties of homocysteine may result from an inability to sustain $S$-NO formation owing to a progressive imbalance between the production of NO by progressively dysfunctional endothelial cells and the levels of homocysteine. ( $J$. Clin. Invest. 1993. 91:308-318.) Key words: thiols • nitric oxide $\bullet$ endothelial cells
\end{abstract}

\section{Introduction}

Elevated levels of the biological thiol homocysteine $(\mathrm{HCYSH})^{1}$ are an independent risk factor for atherosclerosis and are also associated with a variety of thrombotic complica-

Address correspondence to Dr. Joseph Loscalzo, Department of Medicine, Cardiovascular Division, Brigham \& Women's Hospital, 75 Francis Street, Boston, MA 02115.

Received for publication 11 February 1992 and in revised form 30 July 1992

1. Abbreviations used in this paper: CZE, capillary zone electrophoresis; ECB, negatively charged spherical plastic beads; EDRF, endothelium-derived relaxing factor; GFP, gel-filtered platelets; HCYSH, homocysteine; HTL, homocysteine thiolactone; $\mathrm{NO}$, nitric oxide; $\mathrm{NO}_{\mathbf{x}}$, oxides of nitrogen; SNOHO, $S$-nitroso-HCYSH; RS-NO, related $S$-nitrosothiol; PRP, platelet-rich plasma.

The Journal of Clinical Investigation, Inc.

Volume 91, January 1993, 308-318 tions $(1,2)$. Moderate hyperhomocysteinemia is found in 20$30 \%$ of patients with coronary and peripheral vascular disease, and levels of HCYSH may approach 200-250 $\mu \mathrm{M}$ in homocystinuria (2-5). High levels of oxidation products of $\mathrm{HCYSH}$ may further increase significantly the HCYSH-related burden in plasma and the cell cytosol, and thereby contribute to its pathogenicity (6-9). These species include homocysteine disulfide (homocystine), homocysteine mixed-disulfides, and the cyclized oxidation product of $\mathrm{HCYSH}$, homocysteine thiolactone (HTL).

Marked platelet accumulation at sites of vascular injury and platelet-rich occlusive thrombi are distinctive pathologic features of both human and experimental hyperhomocysteinemia (10-12). To explain these pathologic findings, several groups have reported direct proaggregatory effects of $\mathrm{HCYSH}$ and HTL (13-15). These proaggregatory actions, however, have not been demonstrated uniformly (15-18), and supportive biochemical and molecular mechanisms have not been well elucidated. Moreover, the platelet activating effects of $\mathrm{HCYSH}$, attributed to its reactive $\mathrm{SH}$ group, are difficult to reconcile with the known antiplatelet properties of other biological thiols with similar chemical and physical characteristics. In particular, glutathione, cysteine, and $N$-acetylcysteine have antiplatelet effects, albeit at millimolar concentrations $(19,20)$.

Harker and colleagues suggested that HCYSH-induced endothelial injury, by exposing subendothelial connective tissue, represents an alternative mechanism for platelet activation in vivo $(11,12)$. The endothelial cytotoxicity of $\mathrm{HCYSH}$ has since been confirmed (21-23), and attributed to $\mathrm{H}_{2} \mathrm{O}_{2}$ generated by way of the SH group $(21,22)$; direct toxic effects of HTL on endothelial cells have also been reported $(24,25)$. At the same time, however, our understanding of the role played by the endothelium in modulating platelet-vessel wall interaction has changed substantially. It is now widely appreciated that the endothelium plays a dynamic role in counteracting platelet activation by secreting products such as prostacyclin and endothelium-derived relaxing factor (EDRF), the latter having been identified as nitric oxide (NO $[26,27]$ or a closely related $S$-nitrosothiol [RS-NO] [28, 29]).

The disputed chemical nature of EDRF is important in this discussion in that oxides of nitrogen $\left(\mathrm{NO}_{\mathrm{x}}\right)$ react readily with thiols to form $S$-nitrosothiols (30). The recent demonstration of RS-NO formation from endogenous NO (EDRF) (31) provides added evidence in favor of biological relevance for these compounds. $S$-nitrosothiols invariably possess EDRF-like vasodilatory and antiplatelet properties, and the same might be predicted of $S$-nitroso-homocysteine ( $\mathrm{SNOHO}$ ). Moreover, inasmuch as the reactivity of the $\mathrm{SH}$ group is central to the above proposed atherothrombotic mechanisms and the oxidative metabolism of HCYSH, S-nitrosation may represent a biological mechanism for altering favorably the metabolic fate of 
HCYSH. Thus, in light of the potential regulatory importance of the $S$-NO functional group and the controversies regarding the thrombogenic mechanism(s) of $\mathrm{HCYSH}$, we evaluated the effects of HCYSH on platelet-vessel wall interactions, and tested the hypothesis that its thrombogenicity is modulated by $\mathrm{NO}_{x}$ and EDRF. Our results show that HCYSH and HTL have no direct proaggregatory effects; that SNOHO forms under physiologic conditions and possesses EDRF-like properties; that HCYSH-induced thrombogenicity is a consequence of endothelial dysfunction; and that dysfunctional endothelium cannot sustain elaboration of NO sufficient to "detoxify" HCYSH by forming SNOHO. The data strongly support the notion that S-nitrosation of $\mathrm{HCYSH}$ represents an endogenous cytoprotective, antithrombotic cell regulatory mechanism.

\section{Methods}

\section{Materials}

HCYSH, homocystine, HTL (free base and hydrochloride), homocysteic acid, cupric sulfate, ferrous sulfate, methylene blue, Sepharose 2B300 , acetylsalicylic acid, epinephrine, ADP, acetylcholine, $N^{\mathrm{w}}$-nitro-Larginine, and calcium ionophore (A23187) were purchased from Sigma Chemical Co. (St. Louis, MO). Bovine thrombin was obtained from ICN ImmunoBiologicals (Lisle, IL). Sulfanilamide and $\mathrm{N}$-(1naphthyl)ethylenediamine dihydrochloride were purchased from Aldrich Chemical Co. (Milwaukee, WI). Calf skin collagen was obtained from Worthington Biochemical Corp. (Freehold, NJ). Sodium nitrite was purchased from Fisher Scientific Co. (Fairlawn, NJ). NO gas was obtained from Matheson Gas Products (Secaucus, NJ). Radioimmunoassay kits for the determination of cyclic GMP levels were purchased from New England Nuclear (Boston, MA). Hepes-buffered saline consisted of $140 \mathrm{mM} \mathrm{NaCl}, 6 \mathrm{mM} \mathrm{HCl}, 6 \mathrm{mM} \mathrm{N}$-[2-hydroxyethyl]piperazine- $N$-[2-ethane-sulfonic acid], $2 \mathrm{mM} \mathrm{Na} \mathrm{HPO}_{4}, 2 \mathrm{mM}$ $\mathrm{MgSO}_{4}, 0.1 \%$ dextrose, and $0.4 \%$ BSA. PBS consisted of $140 \mathrm{mM}$ $\mathrm{NaCl}, 10 \mathrm{mM}$ sodium phosphate, $\mathrm{pH}$ 7.4. Krebs's buffer consisted of $140 \mathrm{mM} \mathrm{NaCl}, 4.7 \mathrm{mM} \mathrm{KCl}, 2.5 \mathrm{mM} \mathrm{CaCl}_{2}, 1.2 \mathrm{mM} \mathrm{MgSO}_{4}, 1.2 \mathrm{mM}$ $\mathrm{KH}_{2} \mathrm{PO}_{4}, 12.5 \mathrm{mM} \mathrm{NaHCO}$, and $11 \mathrm{mM}$ D-glucose.

\section{Microcarrier endothelial cell culture}

Endothelial cells were isolated from bovine aorta by established techniques (32) and cultured on a microcarrier system of negatively charged spherical plastic beads (ECBs), according to the method of Davies and colleagues (33).

\section{EDRF Generation from cultured cells}

In this method, ECB are stimulated by high shear force to secrete EDRF. The details of this system have been published previously (34). In all experiments, prostanoid synthesis was inhibited with acetylsalicylic acid according to established protocol $(34,35)$. For the purposes of this study, ECB were placed in chambers containing a total volume of $1 \mathrm{ml} \mathrm{PBS} \mathrm{(} \mathrm{pH} \mathrm{7.4)}$ ) at a density of $5 \times 10^{3}$ cells $/ \mu \mathrm{l}$, and exposed to a shear stress of $0.43 \mathrm{dyn} / \mathrm{cm}^{2}$ for $15 \mathrm{~min}$, as we have previously described (34).

\section{Endothelial cell viability}

Assessments of cell growth and degree of endothelial cell confluence on microcarrier beads were routinely studied by phase-contrast microscopy. During the course of experiments, 25- $\mu$ l aliquots of incubation medium were removed at hourly intervals for lactate dehydrogenase measurements, determined spectroscopically (with use of an LD-1 assay kit, Sigma Chemical Co.). At similar intervals, cell viability was assessed by vital dye exclusion with trypan blue (36).

\section{Platelets}

Venous blood was obtained from volunteers who had not consumed nonsteroidal antiinflammatory drugs for at least $10 \mathrm{~d}$, and was anticoag- ulated with $3.4 \mathrm{mM}$ trisodium citrate. Platelet-rich plasma (PRP) was prepared by centrifugation at $150 \mathrm{~g}$ for $10 \mathrm{~min}$ at $25^{\circ} \mathrm{C}$, and plateletpoor plasma was prepared by centrifugation at $800 \mathrm{~g}$ for $10 \mathrm{~min}$. Gelfiltered platelets (GFP) were obtained by passing PRP over a Sepharose-2B column in Tyrode's-Hepes buffer, as previously described (37). Platelet counts were measured using a Coulter counter (model ZN; Coulter Electronics, Hialeah, FL) and were adjusted to 150,000 / $\mu \mathrm{l}$ by the addition of platelet-poor plasma or Hepes-buffered saline.

\section{Platelet aggregation}

Aggregation of PRP and GFP was monitored using a standard nephelometric technique (38) in which 0.3 (GFP) or 0.5 (PRP) ml aliquots of platelets were incubated at $37^{\circ} \mathrm{C}$ and stirred at $1,000 \mathrm{rpm}$ in a PAP-4 aggregometer (Biodata Corp., Hatboro, PA). Aggregations were induced by the addition of varying concentrations of $\operatorname{ADP}(0.75,5$, or 15 $\mu \mathrm{M})$, thrombin $(0.025 \mathrm{U} / \mathrm{ml})$, and collagen $(0.016$, or $0.16 \mathrm{mg} / \mathrm{ml})$, and changes in light transmittance recorded. In typical experiments, platelets were incubated with $\mathrm{HCYSH}$ and its derivatives for $3 \mathrm{~min}$ at $37^{\circ} \mathrm{C}$ before the addition of agonist. In selected experiments, however, preincubations lasted for as long as $1 \mathrm{~h}$. Our methods for examining the effects of EDRF generated from ECBs on platelet aggregation have been published elsewhere in detail (35). Notably, in these experiments, ECBs were preincubated in the presence and absence of HCYSH ( 5 $\mathrm{mM}$ ) in DMEM for $6 \mathrm{~h}$, during which time EDRF-mediated inhibition of platelet aggregation was assayed at hourly intervals. ECBs were washed with PBS to remove HCYSH before their incubation with platelets, and EDRF release stimulated for 3 min by the effects of continuous stirring (flow) in the aggregometer (35). Aggregations were then induced with $5 \mu \mathrm{M}$ ADP. In all cases, aggregation was quantitated by measuring either the maximal rate or extent of change in light transmittance.

\section{Vessel bioassay}

The details of this standard bioassay have been reported previously (39). Briefly, the descending thoracic aortae of New Zealand white female rabbits weighing 3-4 kg were isolated and cleaned of adherent connective tissue. In certain experiments, the endothelium was removed by gently rubbing with a cotton-tipped applicator inserted into the lumen. The rings were mounted on stirrups, suspended in oxygenated $\left(95 \% \mathrm{O}_{2} / 5 \% \mathrm{CO}_{2}\right)$ glass chambers containing $7 \mathrm{ml} \mathrm{Krebs's} \mathrm{buffer}$ at $37^{\circ} \mathrm{C}$, and connected to force transducers (model FTO3C, Grass Instruments, Quincy, MA) which recorded changes in isometric tension. Sustained contractions were induced with $1 \mu \mathrm{M}$ epinephrine after which the direct effects of HCYSH and SNOHO were tested. Concentrations of thiol were confirmed with Ellman's reagent (40). In some cases, methylene blue $(100 \mu \mathrm{M})$ was preincubated with vessel rings for $30 \mathrm{~min}$ before initiation of contraction.

\section{Hydrogen peroxide generation}

Scopoletin serves as a hydrogen donor in the catalyzed reduction of $\mathrm{H}_{2} \mathrm{O}_{2}$ by horseradish peroxidase. In this oxidative reaction, scopoletin fluorescence decreases in direct proportion to $\mathrm{H}_{2} \mathrm{O}_{2}$ concentration in the medium (41). The following assay conditions, designed to detect $\mathrm{H}_{2} \mathrm{O}_{2}$ production from $\mathrm{HCYSH}$, have been published previously (22). Reactions were performed in cuvettes containing $4 \mu \mathrm{M}$ scopoletin in $2.5 \mathrm{ml}$ Krebs's buffer, and were initiated by the addition of $2.2 \mu \mathrm{M}$ horseradish peroxidase. Fluorescence measurements were performed using a spectrofluorimeter (Fluorolog 2 model F11; Spex Industries, Inc., Edison, $\mathrm{NJ}$ ) with sample excitations at $360 \mathrm{~nm}$ and emission at $460 \mathrm{~nm}$.

\section{Cyclic nucleotide assays}

Measurements of cyclic GMP (cGMP) were performed by radioimmunoassay of $400-\mu$ l aliquots of PRP and processed as described previously $(31,35)$. Incubations of HCYSH, SNOHO, and other compounds of interest with cells were conducted for $60 \mathrm{~s}$, and reactions were terminated by the addition of $10 \%$ TCA which was subsequently removed by ether extraction. 


\section{Analytical methods}

Saville reaction. The method of Saville was used for detection of $S$-nitrosothiols (42). The method, which assays $\mathrm{NO}_{\mathrm{x}}$ free in solution, involves a diazotization reaction with sulfanilamide and subsequent coupling with the chromophore $N$-(1-naphthyl)ethylenediamine. The specificity for RS-NOs derives from assay determinations performed in the presence and absence of $\mathrm{HgCl}_{2}$, the latter reagent displacing $\mathrm{NO}$ equivalents for colorimetric reaction in the formation of $\mathrm{RSHg}(42)$.

Ultraviolet/visible spectroscopy. The determination of RS-NO absorption was performed using a Gilford Response UV/VIS spectrophotometer.

Nuclear magnetic resonance spectroscopy. Measurements of RSNOs were made according to the method of Bonnett and colleagues (43). ${ }^{15} \mathrm{~N}-\mathrm{NMR}$ spectra were recorded with a $500 \mathrm{MHZ}$ spectrometer (Bruker Instruments, Inc., Billerica, MA). Deuterium lock was effected with $[\mathrm{D}]_{2} \mathrm{O}$ and the spectra referenced to a $\left[{ }^{15} \mathrm{~N}\right]$ natural abundance spectrum of a saturated solution of $\mathrm{NaNO}_{2}$ at $587 \mathrm{ppm}$. Spectra were recorded at $50.68 \mathrm{MHZ}$ and the nine transients of $16 \mathrm{~K}$ data points collected with a $30^{\circ}$-pulse width and a 10 -s relaxation delay. Data were multiplied by a $2-\mathrm{Hz}$ exponential line broadening factor before Fourier transformation.

Chemiluminescence. Chemiluminescence analyzers operate on the principal that the reaction of NO with ozone results in the emission of detectable light. We have, recently, adapted a highly sensitive new analyzer (TEA model 543; Thermedics, Inc., Woburn, MA) for the purpose of specific RS-NO detection. The details of this method are published elsewhere (44). Briefly, this instrument first uses ultraviolet (UV) photolysis to cleave homolytically NO from parent $S$-nitrosocompounds (in place of chemical reduction used in standard methodology), after which the released NO is separated from other nonvolatile substances in cold traps and carried by $\mathrm{He}$ into the chemiluminescence detector. $S$-nitroso-compounds are readily identified and distinguished from authentic NO by requisite UV photolysis for signal detection. $S$-nitrosothiols are further distinguished from other nitroso-adducts by sample pretreatment with excess $\mathrm{HgCl}_{2}$ under aerobic conditions. By binding to $\mathrm{SH}$ groups selectively, mercuric ion displaces $\mathrm{NO}$ equivalents from RS-NOs (42), with the rapid formation of undetectable higher oxides of nitrogen. Accordingly, RS-NOs are identified by: $(a)$ the requirement of UV photolysis for detection of signal, and $(b)$ the successful elimination of signal by sample pretreatment with $\mathrm{HgCl}_{2}$. The sensitivity of this method for SNOHO detection approaches 0.1 $\mathrm{pM}$ and the reproducibility is within $2 \%$.

High performance capillary zone electrophoresis (CZE). This chemical method for separating HCYSH from its various oxidized and $S$-nitrosated derivatives has been detailed in a recent publication (45). Briefly, isotachophoretic analyses were performed on a capillary system (HPE-100; Bio-Rad Laboratories, Richmond, CA) fitted with a silica-coated capillary $(20 \mathrm{~cm} \times 25 \mathrm{~cm})$. Electrophoretic separations were detected on-line and recorded with a model 1321 single-pen strip chart recorder (model 1321; Bio-Rad) at a chart speed of $1.0 \mathrm{~cm} / \mathrm{min}$ with a rise time of $1 \mathrm{~s}$. Samples were diluted in $0.01 \mathrm{~N} \mathrm{HCl}, 0.01 \mathrm{M}$ sodium phosphate ( $\mathrm{pH} 2.3$ ), and injected using Hamilton syringes. Analyses were performed at $11 \mathrm{kV}$ with the polarity of the internal power supply set for the migration of cations towards the detector (+ polarity). Eluted volumes were monitored at $200 \mathrm{~nm}$ for optimal sensitivity. Confirmatory evidence for $S$-nitrosothiol detection was obtained at $320 \mathrm{~nm}$.

\section{Synthesis and chemical characterization of SNOHO}

The synthesis of SNOHO, to our knowledge, has not been previously described. The compound was prepared by a commonly used method of S-nitrosation $(31,46-48)$ in which HCYSH is treated with an equivalent of acidified $\mathrm{NaNO}_{2}(0.5 \mathrm{~N} \mathrm{HCl})$ at $25^{\circ} \mathrm{C}$. Under these conditions, the general reaction of thiol with oxide of nitrogen is reported to be complete and stoichiometric $(47,48)$. For HCYSH, however, its acidcatalyzed conversion to a lactone derivative (49) is a potential competing reaction that requires examination. Characteristic of other $S$-nitro- sothiols, the above solutions turned red rapidly upon product formation, and displayed distinct absorption maxima at $\sim 250 \mathrm{~nm}, 340 \mathrm{~nm}$, and $550 \mathrm{~nm}(30,31,46-48)$; Fig. $1 A)$. The calculated absorptivity of this compound at $547 \mathrm{~nm}$ is $16.7 \mathrm{M}^{-1}-\mathrm{cm}^{-1}$, and agrees well with the published values of 16.6 and 16.1 for $S$-nitroso-cysteine and $S$-nitrosoglutathione, respectively (46). Using ${ }^{15} \mathrm{~N}-\mathrm{NMR}$ (see above Methods), solutions of HCYSH treated with acidified $\mathrm{Na}\left[{ }^{15} \mathrm{~N}\right] \mathrm{O}_{2}$ exhibited a chemical shift at $750 \mathrm{ppm}$ relative to an internal $\left[{ }^{15} \mathrm{~N}\right]$ standard, indicative of S-NO bond formation $(31,43$; Fig. $1 B$ ). In the Saville reaction (42), the SH/S-NO stoichiometry was $\sim 1.0$. CZE analysis of samples revealed a loss of the peak of HCYSH $(5.94 \pm 0.15 \mathrm{~min}$; Fig. $1 C)$ with coincident generation of a new peak of slower electrophoretic mobility $(7.74 \pm 0.18 \mathrm{~min}$; Fig. $1 \mathrm{D})$. The peak is identified as SNOHO based on its theoretical predicted elution time of $7.2 \mathrm{~min}$ determined from its charge-to-mass ratio (45). Importantly, HTL was not present in reaction solutions (elution time of standard, $2.53 \pm 0.08 \mathrm{~min}$, Fig. $1 E$ ). Taken together, these chemical data provide evidence for stoichiometric S-nitrosation of $\mathrm{HCYSH}$.

In further support of the potential biological relevance of this reaction, SNOHO was synthesized under physiologic conditions. The methods used are reported here; however, other details are discussed within context elsewhere in this paper. In one approach (50), S-nitrosation of HCYSH was achieved in saturated solutions of HYSCH (40 $\mathrm{mM}$ ) containing $0.5 \mathrm{M}$ sodium phosphate ( $\mathrm{pH} 7.4$ ) by brief exposure to authentic NO gas bubbled into solution. In other studies, HCYSH ( 1 $\mathrm{mM}$ ) was incubated with endothelial cells stimulated to secrete EDRF in response to high shear stress, as we have previously published (31). These experiments were conducted in $1 \mathrm{ml}$ PBS at an endothelial cell density of $5 \times 10^{3}$ cells $/ \mu$ l. Cells were exposed to a shear stress of $\sim 0.43 \mathrm{dyn} / \mathrm{cm}^{2}$ for $15 \mathrm{~min}(34)$.

\section{Results}

Homocyst(e)ine and platelet aggregation. The effects of HCYSH on platelet aggregation induced by $\operatorname{ADP}(15 \mu \mathrm{M})$ and collagen $(0.16 \mathrm{mg} / \mathrm{ml})$ are illustrated in Fig. 2. Experiments were performed in PRP taken from eight different volunteers, and unanimously exhibited dose-dependent inhibition of platelet aggregation with an $\mathrm{IC}_{50}$ of $\sim 10 \mathrm{mM}$. Based on theoretical mechanisms proposed to explain the aggregation of platelets by synthetic thiols $(19,51,52)$, specifically, oxy-radical generation and nonspecific surface membrane disulfide reduction, the effects of HCYSH were further examined during incubations for up to $1 \mathrm{~h}$ after additional supplementation with $\mathrm{Cu}^{2+}$ (1-10 $\mu \mathrm{M})$ and $\mathrm{Fe}^{2+}(1-10 \mu \mathrm{M})$ to facilitate SH-dependent superoxide and $\mathrm{H}_{2} \mathrm{O}_{2}$ generation (vida infra). Again, agonistinduced aggregations were inhibited at millimolar concentrations of HCYSH. To preclude possible inactivation of oxy-radicals by plasma reactants, similar experiments were also performed using GFP; and, in view of the potential proaggregatory influence of $\mathrm{H}_{2} \mathrm{O}_{2}$ on primary wave aggregation (52), the effects of HCYSH were also studied using low doses of agonists (see Methods). In both instances comparable antiplatelet effects of thiol were demonstrated. In addition, spontaneous aggregations were not observed under any of the above conditions (data not shown).

The effects of HTL (free base and hydrochloride) on ADPand collagen-induced platelet aggregation are also shown in Fig. 2. The compound, in both forms, demonstrates weak antiplatelet activity. In these studies, stock solutions of the HTL free base were dissolved in $1 \mathrm{~N} \mathrm{HCl}$, and similar results were - demonstrated for the compound dissolved in DMSO (data not shown). Platelet aggregation induced by HTL (free base) in chloroform was shown recently (15) and attributed to the 


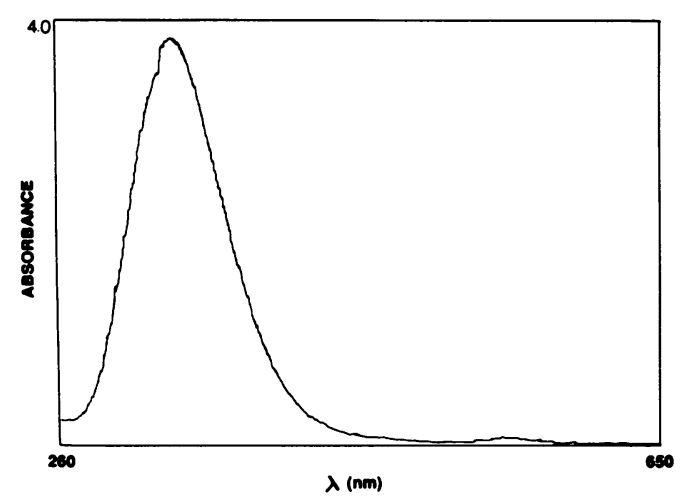

C

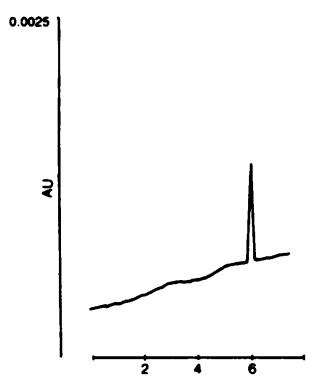

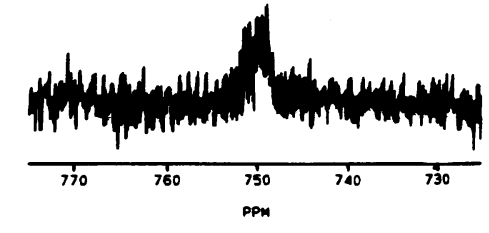

D

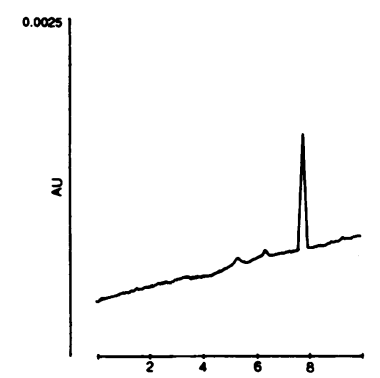

E

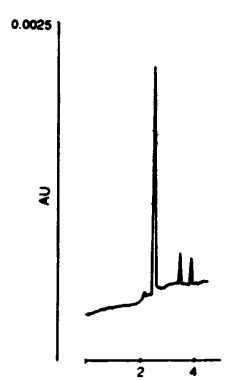

Figure 1. Spectroscopy and chemical characterization of SNOHO. $(A)$ The ultraviolet absorption spectrum of $\mathrm{SNOHO}$ ( $5 \mu \mathrm{M}$ ) reveals the typical absorption maximum of an $S$-nitrosothiol at $338 \mathrm{~nm}$, with a secondary peak at $546 \mathrm{~nm}$. (B) The ${ }^{15} \mathrm{~N}-\mathrm{NMR}$ spectrum demonstrates a chemical shift for SNOHO (referenced to a secondary $\mathrm{Na}\left[{ }^{15} \mathrm{~N}\right] \mathrm{O}_{2}$ standard at $749.5 \mathrm{ppm}$ ). No other chemical shifts were noted. $(C)$ Isotachophoretic analysis (CZE) of HCYSH $(167 \mu \mathrm{M})$, which elutes at $5.94 \mathrm{~min}$. (D) S-nitrosation of HCYSH $(167 \mu \mathrm{M})$ was performed as described in Methods followed by isotachophoretic analysis (CZE). The electropherogram illustrates essentially stoichiometric conversion of HCYSH ( $C, 5.94 \mathrm{~min})$ to $\operatorname{SNOHO}(D, 7.74 \mathrm{~min})$. There is no evidence for formation of HTL, which elutes at $2.5 \mathrm{~min}$ $(167 \mu \mathrm{M}, E)$ under identical conditions. membrane solubility of the compound in this solvent. In our hands, however, control incubations with chloroform alone induced platelet aggregation at a vol \% half that used by these investigators in the absence of HTL. Moreover, the added presence of HTL did not increase the aggregation response compared to chloroform alone. In other studies, we induced acidcatalyzed conversion of HCYSH to HTL $(6 \mathrm{~N} \mathrm{HCl})(49)$ and tested the effects of HTL generated in this manner on platelet aggregation. The effects observed were analogous to those shown in Fig. 2. Homocystine and homocysteic acid had no effect on ADP-induced platelet aggregation in PRP at concentrations up to $10 \mathrm{mM}$, confirming previous reports (13, $15,16)$.

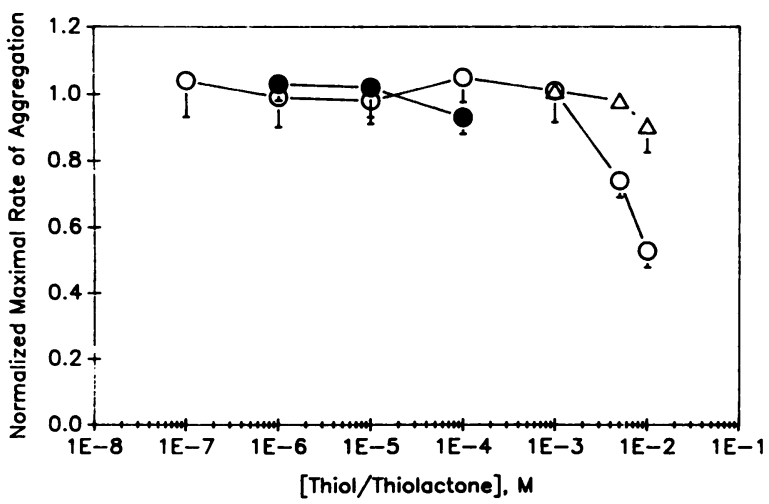

SNOHO and platelet aggregation. SNOHO was prepared by treatment of HCYSH with acidified nitrite as described in Methods. The solutions were neutralized by dilution in PBS ( $\mathrm{pH} 7.4$ ) and then incubated in PRP. As depicted in Fig. 3, SNOHO markedly inhibited platelet aggregation. In control experiments using equivalent concentrations of $\mathrm{NaNO}_{2}$, no significant inhibition of platelet aggregation was observed (normalized extent of aggregation for $\mathrm{NaNO}_{2} \quad\left[\begin{array}{ll}100 & \mu \mathrm{M}\end{array}\right]$ $=1.02 \pm 0.12 ; n=12$ ).

SNOHO and cyclic GMP. Inasmuch as the antiplatelet effects of EDRF, NO, and other nitroso-compounds are mediated through increases in intracellular cyclic GMP (53), the effects of SNOHO on platelet cyclic GMP were studied. Incu-

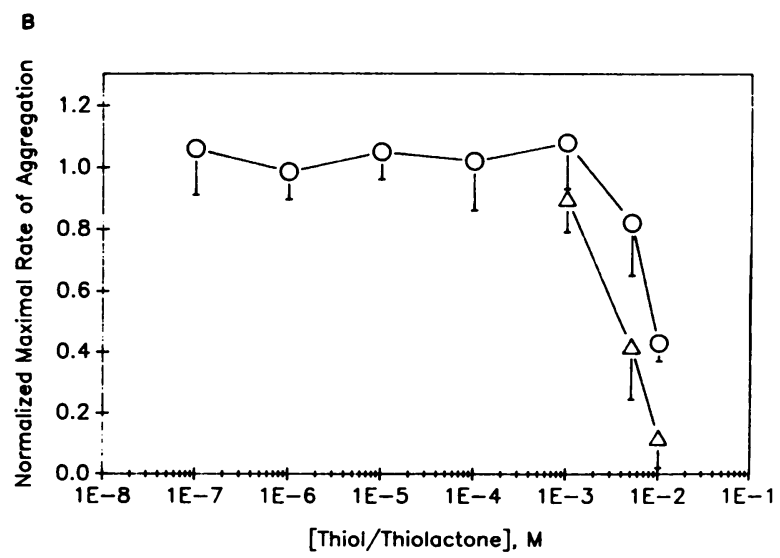

Figure 2. Platelet inhibition of HCYSH and HTL. Dose-effect curves for platelet inhibition by HCYSH (O), HTL (free base) ( $\bullet$ ), and HTL (hydrochloride) $(\Delta)$ plotted as normalized maximal rate of aggregation relative to control. Platelet aggregation in PRP was induced with $(A)$ $15 \mu \mathrm{M}$ ADP or $(B) 0.16 \mathrm{mg} / \mathrm{ml}$ collagen. Data are presented as mean $\pm \mathrm{SD}$. ( $n=$ eight different subjects). 


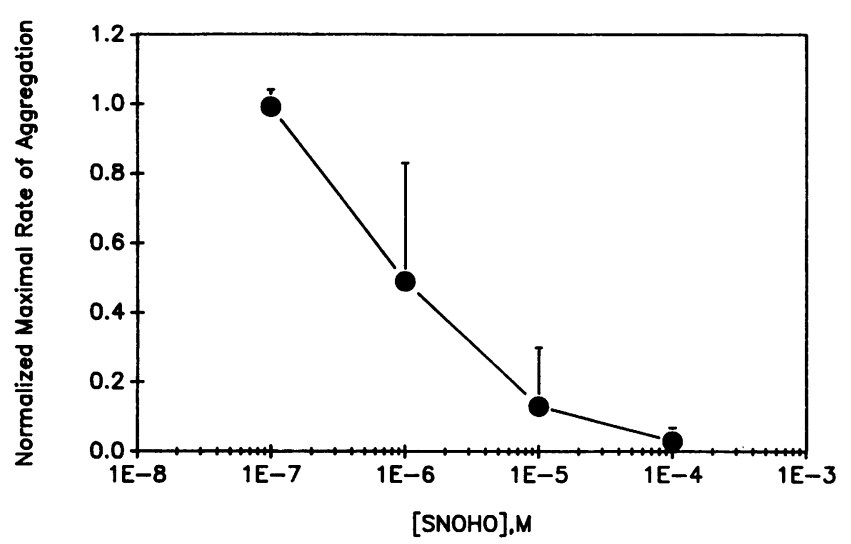

Figure 3. Dose-dependent inhibition of platelet aggregation by SNOHO. Dose-effect curves for platelet inhibition, plotted as normalized maximal rates of platelet aggregation relative to control, were generated in response to platelet aggregation by $0.16 \mathrm{mg} / \mathrm{ml}$ collagen. Data are presented as mean \pm SD. $(n=$ six different subjects $)$.

bation of SNOHO $(100 \mu \mathrm{M})$ in PRP for $60 \mathrm{~s}$ resulted in a 3.6-fold increase in intracellular platelet cyclic GMP above basal levels $(P<0.05)$. Equivalent concentrations of $\mathrm{NaNO}_{2}$ and HCYSH had no significant effect on platelet cyclic GMP (Table I).

HCYSH: Oxidative metabolism and reactivity towards oxides of nitrogen. Further studies were undertaken to elucidate the reactivity of sulfur in oxidized derivatives of HCYSH toward $\mathrm{NO}_{\mathbf{x}}$. To recall, S-nitrosation of HCYSH in acidified nitrite was verified by several analytical methods (see Methods). Synthesis of SNOHO was also achieved in phosphate buffer $(0.5 \mathrm{M}, \mathrm{pH} 7.4)$ into which authentic NO gas was bubbled. Solutions turned red upon product formation, and the characteristic spectroscopic absorption maxima for SNOHO (Fig. 1 $A$ ) were observed. Using both of these S-nitrosation methods, it was determined that homocystine does not react to form an $S$-nitrosothiol. Similarly, as determined by CZE and in complementary Saville assays, the ring sulfur of HTL is not amenable to electrophilic attack by $\mathrm{NO}_{x}$. Importantly, however, S-nitrosation of HCYSH prevented ring closure (thiolactone formation ) in the acid-catalyzed reaction: incubations of HCYSH in acidic milieux $(1-12 \mathrm{~N} \mathrm{HCl})$ resulted in acid- and time-depen-

Table I. S-NO-Homocysteine and Platelet Cyclic GMP

\begin{tabular}{lc}
\hline & Cyclic GMP \\
\hline & pmol/10 platelet \\
Control & $2.14 \pm 0.64$ \\
$\mathrm{NaNO}_{2}$ & $2.78 \pm 1.07$ \\
$\mathrm{HCYSH}$ & $2.34 \pm 0.25$ \\
SNOHO & $7.80 \pm 0.92^{*}$ \\
\hline
\end{tabular}

Platelet cyclic GMP production and SNOHO. Exposure of platelets (PRP) to $100 \mu \mathrm{M}$ SNOHO for $60 \mathrm{~s}$ resulted in significant elevations in intracellular platelet cyclic GMP. Neither HCYSH (unmodified) nor $\mathrm{NaNO}_{2}$ (used as the source of $\mathrm{NO}$ equivalents for synthesis of SNOHO) exhibited any significant effect on platelet cyclic GMP at equivalent $(100 \mu \mathrm{M})$ concentrations. Results are expressed as mean \pm SD for four experiments each performed in duplicate. dent formation of HTL as previously reported (49), which did not occur in the added presence of equimolar $\mathrm{NaNO}_{2}$. Under these circumstances, SNOHO formed to the exclusion of HTL and subsequent conversion to HTL was not observed over the time course of several hours as determined by CZE and by the Saville reaction. These data indicate that a free sulfhydryl group is a requirement for S-nitrosation of $\mathrm{HCYSH}$, and suggest that SNOHO formation and the oxidative metabolism of HCYSH are reactions that occur exclusively of one another.

$E D R F, S N O H O$, and platelet inhibition. Effluent from ECB stimulated by high shear force to secrete EDRF in the presence and absence of HCYSH ( $1 \mathrm{mM})$ were analyzed by the chemiluminescence and Saville methods for the formation of $S$-nitrosothiol. Quantitative concordance between the two methods was observed with SNOHO measuring $0.81 \pm 0.24 \mu \mathrm{M}$ by chemiluminescence (Fig. 4) and $0.92 \pm 0.43 \mu \mathrm{M}$ by Saville (mean $\pm \mathrm{SD} ; n=5$ ); the greater variation among measurements by the method of Saville being accounted for by its lower sensitivity $(100 \mathrm{nM})$. To assay the bioactivity of these samples, 100- $\mu$ l aliquots of ECB effluent were incubated with PRP (200 $\mu \mathrm{l})$ for $10 \mathrm{~min}$, and aggregations induced with $\operatorname{ADP}(5 \mu \mathrm{M})$. Platelet inhibition induced by ECB stimulated to secrete EDRF in the presence of HCYSH is illustrated in Fig. 5. The treatment of ECB with the NO synthase inhibitor $N^{\mathrm{w}}$-nitro-Larginine $(200 \mu \mathrm{M})$ entirely prevented the formation of $S$-nitrosothiol (i.e., below limits of detection) and attenuated the degree of platelet inhibition by $81 \pm 15 \%$ (mean $\pm \mathrm{SD} ; n=3 ; P$ $<0.001$ ). As further evidence that SNOHO is the active species in these studies, the degree of platelet inhibition observed corresponded with that predicted from the SNOHO dose-response relationship based on the S-NO concentration of the solutions (Fig. $5 \mathrm{~B}$ ). Moreover, it is notable in the context of an EDRF half-life of 5-30 s $(26-29,31,34)$ that the time delay in ECB-effluent transfer to PRP in these studies was $\sim 5 \mathrm{~min}$, and that the bioactivity of samples was fully preserved with a 30-min time delay, as well $(n=2)$; in the absence of added HCYSH, effluent from stimulated ECB did not significantly inhibit platelet aggregation $(P=\mathrm{NS})$. These findings are consistent with the stability of SNOHO under physiologic conditions (Fig. 6). Taken together these experiments are interpreted as follows: $(a)$ exposure of $\mathrm{HCYSH}$ to endogenous $\mathrm{NO}_{\mathbf{x}}$ results in the formation of SNOHO; $(b)$ brief exposure of endothelial cells to HCYSH engenders antiplatelet activity through formation of SNOHO; and $(c)$ HCYSH preserves (stabilizes) NO and EDRF-like bioactivity by forming SNOHO.

$E D R F$ and HCYSH-related platelet aggregation. In the absence of a detectable direct, proaggregatory effect of $\mathrm{HCYSH}$, we tested the hypothesis that HCYSH-mediated endothelial cell dysfunction leads secondarily to platelet activation. For this purpose, ECB were incubated with HCYSH ( $5 \mathrm{mM}$, Weymouth's medium) for up to $6 \mathrm{~h}$; HCYSH was excluded from the medium in time-control experiments. At regular intervals, ECB $\left(1 \times 10^{6}\right.$ cells $)$ were removed, washed in PBS, and added to PRP. EDRF secretion was stimulated by stirring in the aggregometer for $3 \mathrm{~min}$ (35), and aggregation induced with ADP $(5 \mu \mathrm{M})$. The results depicted in Fig. 7 reveal that with prolonged ( $4 \mathrm{~h}$ ) exposure to HCYSH, ECB lose their innate capacity to inhibit platelet aggregation through secretion of EDRF. Measurements of lactate dehydrogenase released into the medium revealed modest $(<20 \% / 6 \mathrm{~h})$ increases over time and no difference between HCYSH-exposed and control ECBs. Similarly, no difference in cell detachment from microcarriers or in 

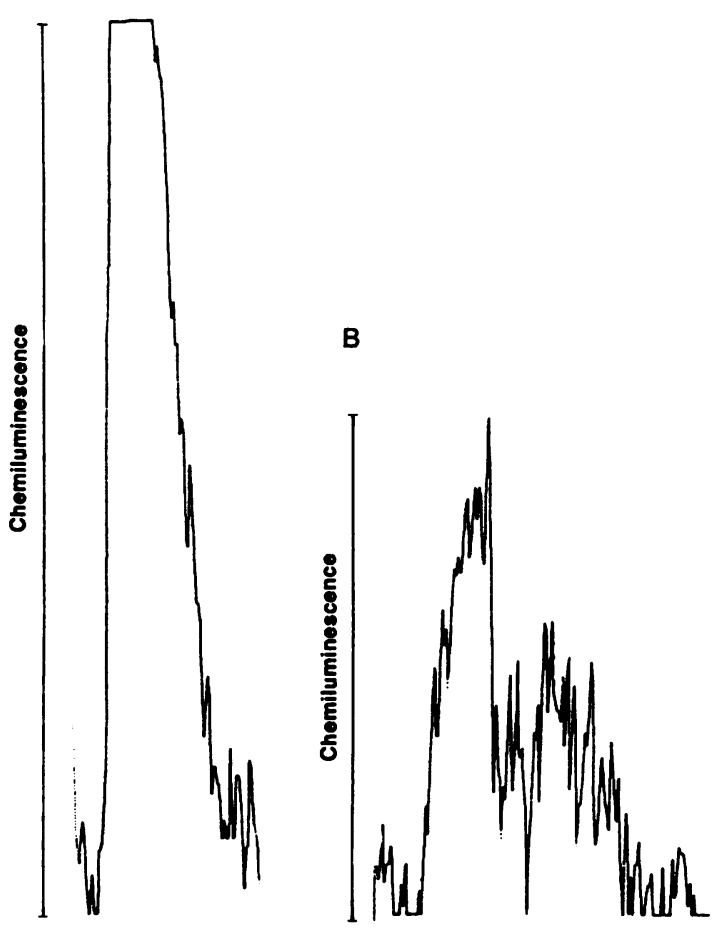

$$
\text { C }
$$

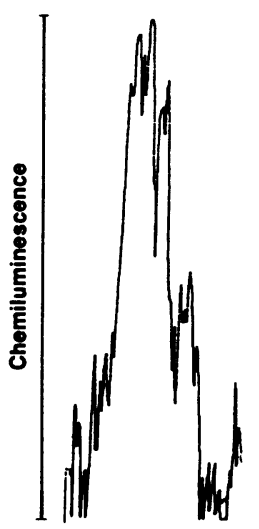

Figure 4. Detection of SNOHO formation from endogenous $\mathrm{NO}_{\mathbf{x}}$. Endothelial cells were stimulated by high shear forces to secrete EDRF for $15 \mathrm{~min}$ (as described in Methods) in the presence $(A, B)$ or absence $(C, D)$ of $1 \mathrm{mM}$ HCYSH. Effluent was then transferred within $10 \mathrm{~min}$ for analysis by chemiluminescence. $(B)$ and $(D)$ are paired samples of $(A)$ and (C), respectively, after their pretreatment with $\mathrm{HgCl}_{2}$, which displaces NO selectively from thiol adducts. $\mathrm{HgCl}_{2}$ is shown to attenuate significantly the signal from HCYSH-exposed cells ( $A$ vs. $B$ ) but has little effect on signal in the absence of HCYSH ( $C$ vs. $D$ ). The signal is also greatly reduced (seven-fold) in the absence of added thiol ( $A$ vs. $C$ ), which is compatible with the oxidation of free NO to higher oxides which are not detected sensitively by chemiluminescence. Note that the relative gain in $B, C$, and $D$ is twice that in $A$. RS-NO-derived NO was only detected after photolytic cleavage of the S-NO bond; signal was not detected when the photolysis lamp was turned off. Quantification of RS-NO in these experiments is provided in the text. trypan blue exclusion was detectable in the presence of HCYSH under these experimental conditions.

$\mathrm{HCYSH}, \mathrm{SNOHO}$, and $\mathrm{H}_{2} \mathrm{O}_{2}$ generation. There is strong evidence and agreement among studies that $\mathrm{HCYSH}$ injures endothelial cells by generating $\mathrm{H}_{2} \mathrm{O}_{2}$, and that its toxicity is prevented by $\mathrm{H}_{2} \mathrm{O}_{2}$ elimination $(21,22)$. As part of elegant work supportive of this biochemical mechanism, it was shown that the thiol autooxidizes in a two-electron transfer to $\mathrm{O}_{2}$ with
A

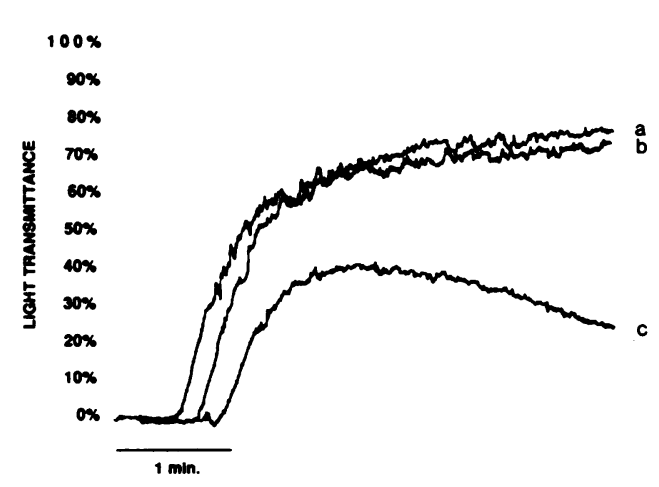

B

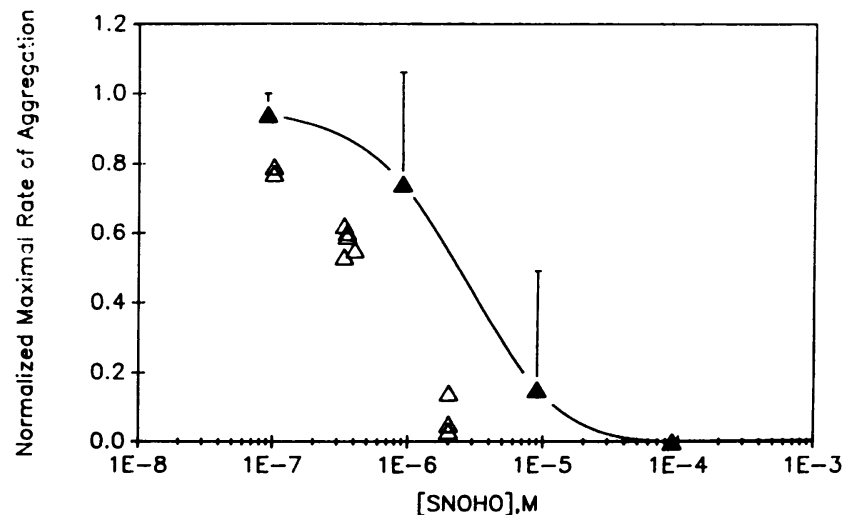

Figure 5. Stabilization of NO bioactivity through formation of SNOHO with HCYSH, and bioactivity of endogenously derived SNOHO in platelet aggregation studies. SNOHO was synthesized by incubation of HCYSH (1 mM) with endothelial cells stimulated to secrete EDRF for $15 \mathrm{~min}$ as described in Methods and Fig. 6. Effluent $(100 \mu \mathrm{l})$ was then transferred to PRP $(200 \mu \mathrm{l})$ within 5 min and aggregations induced with $5 \mu \mathrm{M}$ ADP. Concomitantly, chemical quantification of RS-NO in samples was performed. $(A)$ demonstrates platelet inhibition by $350 \mathrm{nM}$ RS$\mathrm{NO}$ (c) relative to a control aggregation (a). HCYSH, exposed to unstimulated endothelial cells for 15 min, had little effect on platelet aggregation (b), and RS-NO formation was not detectable chemically. In the absence of added thiol, effluent from cells stimulated to secrete EDRF had no significant effect on platelet aggregation (normalized rate of aggregation $=0.98$ compared to control, $n=2)$. $(B)$ shows the dose-effect relationship for platelet inhibition by SNOHO synthesized from acidified $\mathrm{NaNO}_{2}$ and $\operatorname{EDRF}(\Delta)$. The open triangles are each representative of single experiments in which SNOHO was synthesized by exposure of HCYSH to endothelial cells as described above. The degree of inhibition by endogenously derived RS-NO is seen to correlate well with that predicted from the dose-response relationship for chemically synthesized SNOHO. 


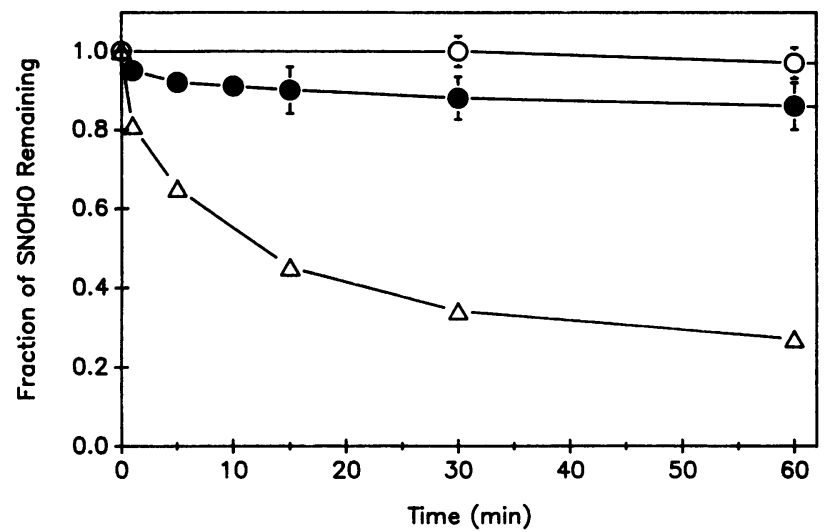

Figure 6. Stability of SNOHO. SNOHO was synthesized with acidified $\mathrm{NaNO}_{2}$ and then diluted in $10 \mathrm{mM}$ phosphate buffer or plasma. The stability of SNOHO was determined over time at $\mathrm{pH} 7.4(\bullet)$ and $\mathrm{pH} 2.5(\mathrm{O})$ by monitoring the absorbance at $336 \mathrm{~nm}$. In human plasma $(\Delta)$, SNOHO was measured after protein precipitation according to the method of Saville (42).

formation of $\mathrm{H}_{2} \mathrm{O}_{2}$ (22). We therefore tested the hypothesis that S-nitrosation, by blocking the $\mathrm{SH}$ group with $\mathrm{NO}$, would limit $\mathrm{H}_{2} \mathrm{O}_{2}$ generation. Confirmatory results are shown in Fig. 8. HCYSH induced a rapid loss of scopoletin fluorescence indicative of $\mathrm{H}_{2} \mathrm{O}_{2}$ generation. In marked contrast, $\mathrm{H}_{2} \mathrm{O}_{2}$ production from $\mathrm{SNOHO}$ is negligible, even in the presence of a metal catalyst. Thus, the cytotoxic mechanism of HCYSH through $\mathrm{H}_{2} \mathrm{O}_{2}$ production is attenuated by $\mathrm{S}$-nitrosation.

SNOHO and vessel relaxation. The effects of SNOHO were further examined in the vessel bioassay. As illustrated in Fig. 9 and Table II, the compound is an active vasodilator with an $\mathrm{IC}_{50}$ of $250 \mathrm{nM}$. Indicative of the potency of this S-NO adduct, the $\mathrm{IC}_{50}$ of $S$-nitroso-L-cysteine in this system is $4 \mu \mathrm{M}$. Consistent with a cyclic GMP-dependent mechanism of action, relax-

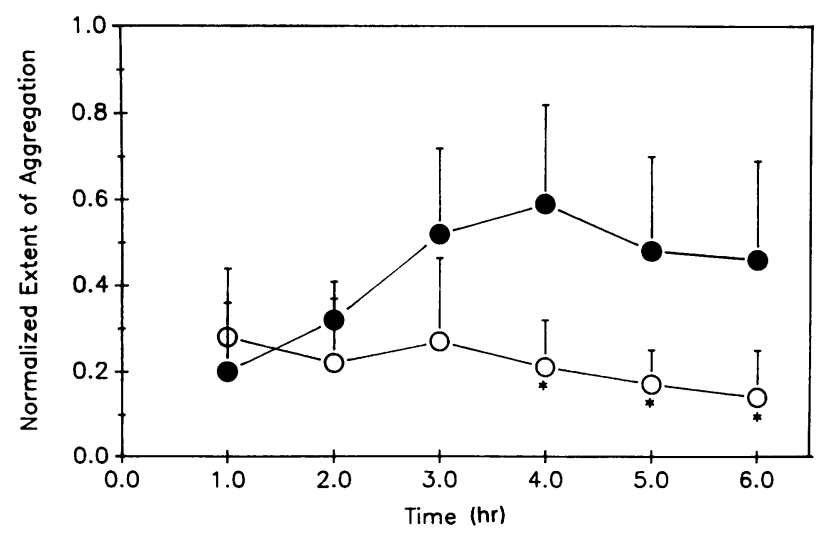

Figure 7. HCYSH-mediated attenuation of platelet inhibition by EDRF. Endothelial cells (ECB) were incubated in the presence $(\bullet)$ or absence $(0)$ of $5 \mathrm{~mm}$ HCYSH for up to $6 \mathrm{~h}$ in Weymouth's culture medium. At hourly intervals, $8.8 \times 10^{5}$ cells were removed, washed, and incubated with platelets for 3 min during which time EDRF secretion was stimulated by stirring in the aggregometer. Aggregations were then induced with $5 \mu \mathrm{M}$ ADP, and the normalized extent of aggregation plotted for $n=3$ experiments as mean $\pm \mathrm{SD}$. These curves are significantly different from one another by ANOVA to $P<0.01$, and the 4-6-h time points are different from one another to $P<0.01$ by Newman-Keul's comparison.

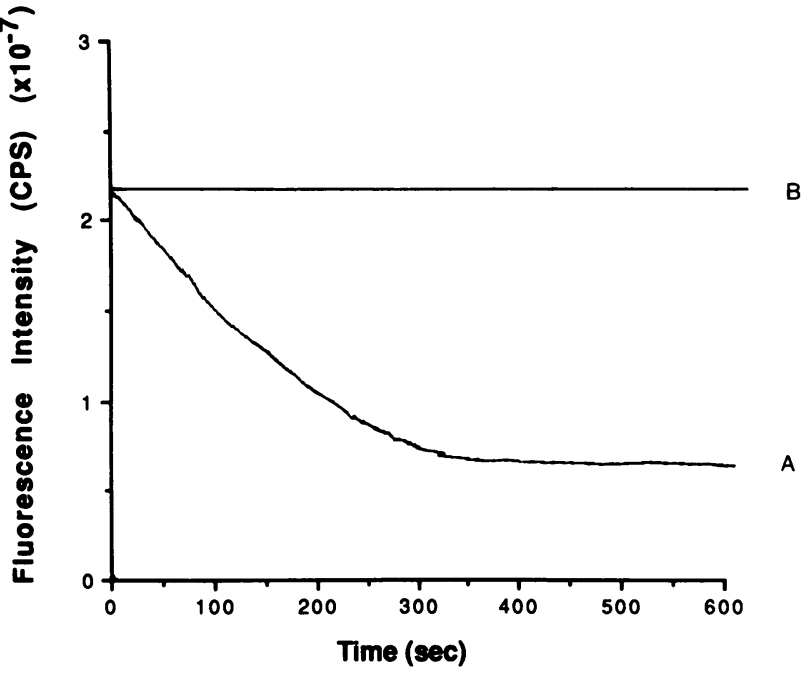

Figure $8 . \mathrm{H}_{2} \mathrm{O}_{2}$ generation by $\mathrm{HCYSH}$ and its prevention by S-nitrosation. The generation of $\mathrm{H}_{2} \mathrm{O}_{2}$ was detected by extinction of scopoletin fluorescence during its oxidation by horseradish peroxidase over a 10-min period. The maximal rate of fluorescence extinction is proportional to the concentration of $\mathrm{H}_{2} \mathrm{O}_{2}$ in solution; $\mathrm{HCYSH}$ ( 500 $\mu \mathrm{M}$ )-mediated $\mathrm{H}_{2} \mathrm{O}_{2}$ generation $(A)$ is prevented by $\mathrm{S}$-nitrosation $(B)$. The initial rates $(\mu \mathrm{M} / \mathrm{min})$ of $\mathrm{H}_{2} \mathrm{O}_{2}$ generation by $\mathrm{HCYSH}$ in the presence and absence of $5 \mu \mathrm{M} \mathrm{Cu}^{2+}$ are $0.16 \pm 0.013$ and $0.11 \pm 0.04$, respectively (mean $\pm \mathrm{SD} ; n=3$ ). The initial rates were 0 $\mu \mathrm{M} / \mathrm{min}$ for $\mathrm{SNOHO}$ and were unchanged by the addition of $5 \mu \mathrm{M}$ $\mathrm{Cu}^{2+}(n=3)$.

ations by $\mathrm{SNOHO}$ were prevented by the guanylate cyclase inhibitor, methylene blue (data not shown). Thus, these relaxation responses to SNOHO are reminiscent of NO and EDRF $(26,31)$.

\section{Discussion}

Thrombosis is a well recognized complication of hyperhomocysteinemia $(1,2,5)$. The thrombogenic mechanism(s) of this disorder, however, are not well understood, and the related literature is often controversial. In particular, reports on the direct effects of HCYSH and its derivatives on platelet aggregation are conflicting and inconclusive. McDonald and colleagues first demonstrated increased platelet "stickiness" in the blood of homocystinurics, and by the addition of homocystine to plasma (13). Changes in platelet adhesiveness, however, have not been confirmed subsequently by other groups (5456 ). Several groups have also failed to demonstrate aggregation

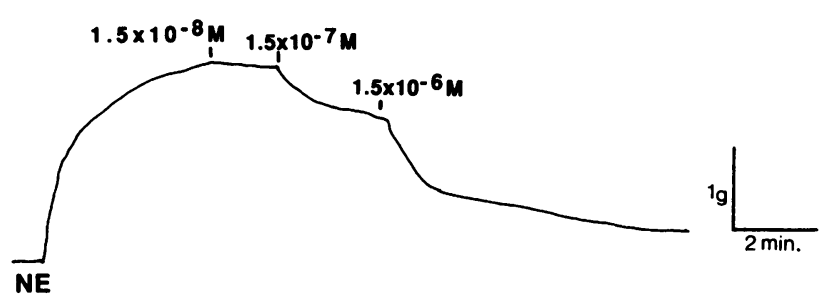

Figure 9. SNOHO-induced vasorelaxation. Deendothelialized rabbit aortae were contracted with epinephrine $(1 \mu \mathrm{M})$ and relaxations induced with SNOHO in a dose-dependent manner. 
Table II. Vasorelaxation by S-NO-Homocysteine

\begin{tabular}{lccc}
\hline & \multicolumn{3}{c}{ Percent relaxation } \\
\cline { 2 - 4 } & $\mathrm{NaNO}_{2}$ & HCYSH & SNOHO \\
\hline $15 \mathrm{nM}$ & 0 & 0 & $6 \pm 4$ \\
$150 \mathrm{nM}$ & 0 & 0 & $33 \pm 10$ \\
$1.5 \mu \mathrm{M}$ & $7 \pm 7$ & 0 & $85 \pm 3$ \\
\hline
\end{tabular}

S-NO-homocysteine (SNOHO) was synthesized from acidified $\mathrm{NaNO}_{2}$ and $\mathrm{HCYSH}$ at equimolar concentrations as described in Methods. Values are expressed as mean \pm SD. $n=3$.

of platelets by homocystine $(13,15,16)$. The effects of HCYSH have not been well studied. HCYSH has been reported to increase thromboxane production in platelets (14), and proaggregatory properties of the thiol have been suggested $(14,57)$. In a contrasting report, however, McCully and Carvalho were unable to demonstrate $\mathrm{HCYSH}$-induced platelet aggregation (15). Notwithstanding the negative findings of the latter report (15), it should be noted that these conclusions were based on studies in only two subjects.

The effects of HTL on platelet function are particularly controversial. Early studies testing the thrombogenic properties of HTL showed that the compound had little effect on platelet aggregation (16). More recently, the free base of HTL was reported to cause platelet aggregation, and its prothrombotic properties clearly distinguished from those of the inactive polar salt (hydrochloride) (15). The authors reasoned that the lipid soluble properties of the free base were responsible for platelet activation. In an entirely different context, HTL has been shown to act synergistically with other methyl transferase inhibitors to inhibit platelet aggregation $(58,59)$.

In this study, we demonstrate that HCYSH does not cause platelet aggregation directly. Moreover, our findings of dosedependent inhibition of platelet aggregation by $\mathrm{HCYSH}$ are in keeping with the inhibitory properties of other low molecular weight biological thiols, notably cysteine and glutathione (19). The remarkable similarity in the inhibitory potency among these thiols further bespeaks their similar physiochemical properties and a common mechanism of action. Inasmuch as plasma levels of acid-soluble thiol do not achieve concentrations sufficient to inhibit platelet aggregation (58), the biological relevance of this effect is in question. We also demonstrate weak platelet inhibitory properties of HTL. We did not find the platelet bioactivity of the HTL free base to be significantly different from that of the salt. Thus, we attribute the previous findings of HTL (free base)-induced platelet activation (15) to the effects of the chloroform solvent employed. In light of our results, we now conclude that there is internal consistency as well as general agreement among studies: HTL has little effect on platelet aggregation at concentrations less than millimolar $(16,58)$; at higher concentrations (Fig. 2) or in the presence of a methylation inhibitor with which HTL acts synergistically $(59,60)$, platelet inhibition is observed. Platelet inhibition by HTL might be explained in part by hydrolytic cleavage of the lactone under physiologic conditions (61) (by our estimate, $t_{1 / 2}=10 \mathrm{~min}$ at $\mathrm{pH} 7.4$, data not shown) with generation of inhibitory concentrations of HCYSH. Finally, we confirm the work of many others that homocystine does not affect platelet aggregation $(13,15,16)$. Taken together, our data provide no evidence that the thrombotic tendencies associated with hyperhomocyst(e)inemia derive from a direct effect of HCYSH or its oxidized derivatives on platelets.

Endothelial injury is an alternative explanation for thrombogenicity associated with hyperhomcyst(e)inemia. Several groups have reported that HYCSH and HTL are toxic to endothelial cells in culture $(21-23,62)$, and by continuous infusion in animal models $(11,24,25,63)$. We defined cytotoxicity (and consequent thrombogenicity) in terms of functional bioassay responses to EDRF, finding an inverse relationship between the capacity to secrete EDRF and a thrombogenic mechanism through platelet activation. Specifically, during prolonged exposure to HCYSH, we observed progressive impairment in the capacity of the endothelium to inhibit maximally platelet aggregation. Thus, we have shown for the first time a causal relationship between HCYSH-mediated endothelial dysfunction and a predisposition to platelet activation. At the same time, our data are in keeping with previous observations that the thrombotic tendencies in hyperhomocysteinemia do not necessarily impart a supranormal aggregation response $(11,12)$.

The interaction between EDRF (or a derivative thereof) and HCYSH was further explored in detail. We $(34,35)$ and, more recently, others (64) have reported that biological thiols potentiate the bioactivity of EDRF. There is ample evidence in this regard that thiols react with $\mathrm{NO}_{\mathrm{x}}$ to form $S$-nitrosothiols $(28,29,46,53)$. In support of biological relevance for SNOHO, we have now demonstrated HCYSH-dependent $S$ nitrosothiol formation from endogenously derived $\mathrm{NO}_{\mathbf{x}}$. Moreover, this S-NO adduct possesses potent antiplatelet and vasodilatory properties, mediated through cyclic GMP reminiscent of EDRF. The unusual stability of SNOHO under physiologic conditions vis a vis the half-life of NO is a noteworthy distinguishing characteristic of this compound and suggests a mechanism by which the endogenous bioactivity of NO is preserved. Thus, we propose that the endothelium can counteract the thrombogenic mechanism(s) of HCYSH through secretion of EDRF, and that the formation of SNOHO is fundamental to this counterregulatory pathway. These data are also supportive of the hypothesis that the endogenous formation of SNOHO may play an integral role in the hemostatic process through platelet inhibition and vasorelaxation.

$\mathrm{HCYSH}$-induced endothelial injury in cell culture derives in large part (if not entirely) from $\mathrm{H}_{2} \mathrm{O}_{2}$ generated by way of the $\mathrm{SH}$ group $(21,22)$. Inasmuch as biochemical measurements of $\mathrm{H}_{2} \mathrm{O}_{2}$ generation correlate directly with the cytotoxicity of HCYSH in these studies (22), it is noteworthy that S-nitrosation of HCYSH effectively inhibits sulfhydryl-dependent $\mathrm{H}_{2} \mathrm{O}_{2}$ generation. Thus, these observations, taken together with our findings of SNOHO formation in the presence of EDRF, suggest a novel mechanism by which the endothelium can modify the toxicity of sulfur-containing amino acids. In this context, the atherogenecity of HCYSH imparted by its oxidative metabolism to a thiolactone $(15,24,25)$ may be accounted for, at least in part, by the inaccessibility of lactone sulfur (in an ester linkage) to electrophilic attack by $\mathrm{NO}_{\mathbf{x}}$. Additional experiments are in order to determine the regulation of the apparently competing pathways of $S$-nitrosothiol synthesis and HCYSH oxidation to HTL.

Our findings introduce several theoretical issues worthy of consideration. The concept that NO may modulate the pathogenicity of HCYSH raises the possibility that the toxic manifes- 


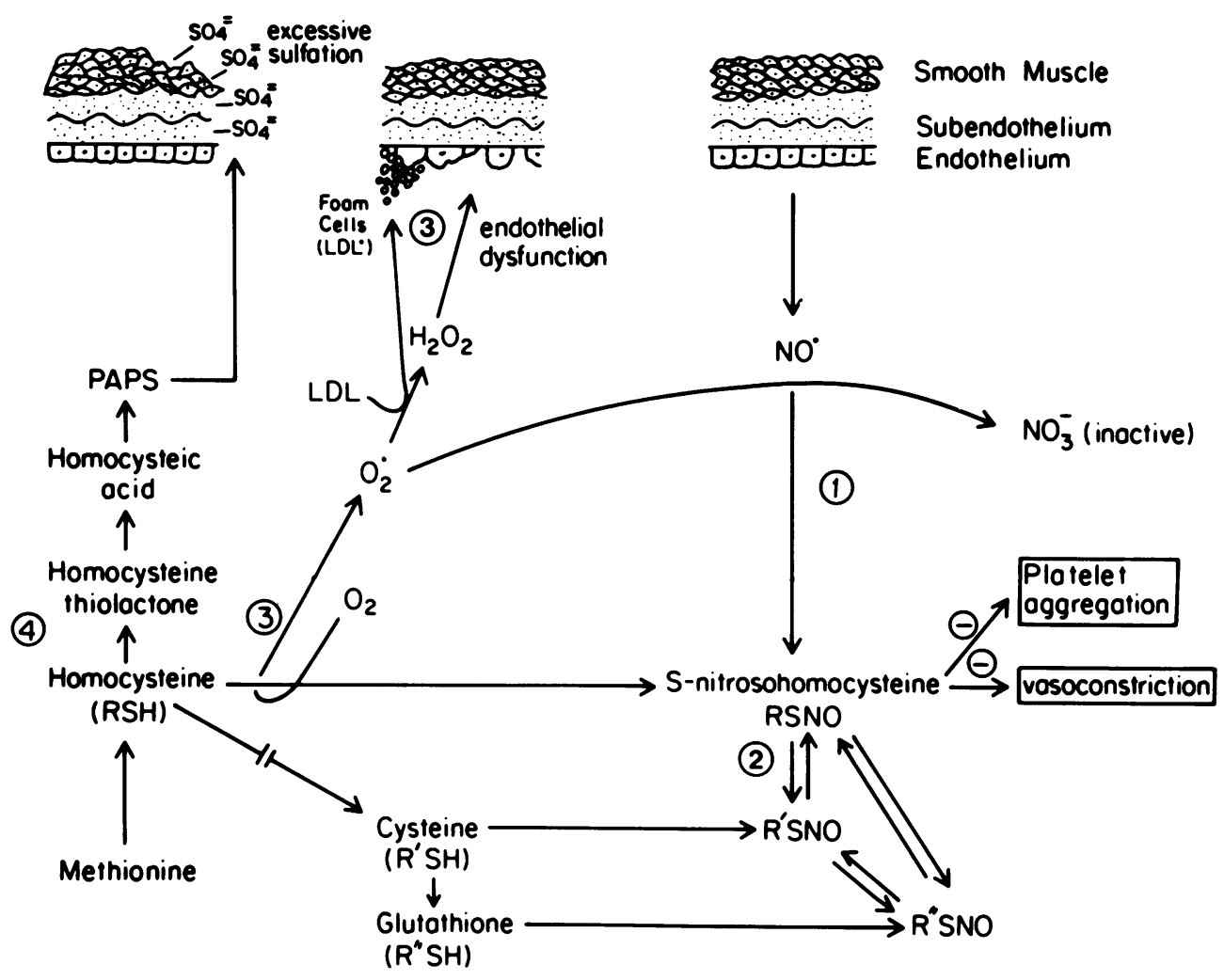

Figure 10. Proposed mechanism of HCYSH-mediated atherothrombosis and its modulation by NO. (1) HCYSH reacts with NO equivalents derived from endothelium to form a vasodilatory, antiplatelet S-nitrosothiol adduct. (2) SNOHO is one of several potential biological RSNOs which may react through thiol-nitrosothiol exchange to serve as a pool of molecules active for relaxation and platelet inhibition in plasma and the cell cytosol. (3) In disease states in which HCYSH levels are elevated or NO release is compromised, HCYSH ( free SH) may damage endothelium through generation of $\mathrm{H}_{2} \mathrm{O}_{2}$, thereby embarrassing NO production; by a similar oxy-radical-dependent mechanism, HCYSH may facilitate oxidation of LDL and its recognition by the scavenger receptor. (4) With a relative NO deficit, $\mathrm{HCYSH}$ is shunted toward oxidative metabolism to HTL; this pathway leads to further vessel wall damage at least,

in part, through excessive sulfation of connective tissue $(9,25)$. In this paradigm, HCYSH plays an indirect causal role in platelet activation and vasoconstriction by disarming the endogenous counterregulatory mechanisms of EDRF generation and RS-NO formation. (// = classic enzymatic block in homocystinuria [cystathionine beta-synthetase deficiency]).

tations of HCYSH reflect an imbalance between NO availability and HCYSH levels. Accordingly, an NO-free thiol index may provide a more accurate measure of the pathogenic potential of HCYSH than the absolute level of "thiol excess." Defined as such, hyperhomocysteinemia may indicate a relative deficiency of $\mathrm{NO}$ ( as a result of endothelial injury). The mechanism of hyperhomocysteinemia notwithstanding, the resultant endothelial damage would predictably embarrass NO production and, consequently, set a cycle in motion in which the antithrombotic cytoprotective mechanisms of S-nitrosation are increasingly compromised at the expense of a predisposition to atherosclerosis and thrombosis (Fig. 10). We also entertain the possibility that the cytoprotective mechanism of S-nitrosation may play a more general role in modulating the atherogenecity of other sulfur-containing amino acids. Cysteine, for example, is highly toxic to cells in culture (65), also supports the generation of reactive oxygen species $(66,67)$, and has been strongly implicated in atherogenesis through modification of low density lipoproteins to a form recognized by the scavenger receptor $(66,67)$. The little appreciated toxicity of cysteine is especially pertinent in this context in light of recent attention paid to its S-nitrosated derivative, $S$-nitroso-L-cysteine. The vasodilatory and antiplatelet properties of this molecule have been important considerations in the claims for its identity as EDRF (28). Thus, S-nitrosation may represent one such cytoprotective cell regulatory mechanism that simultaneously confers upon biological thiols EDRF-like bioactivity.

In summary, the data presented show the following: $(a)$ HCYSH and HTL are, in fact, weak platelet inhibitors and do not directly promote platelet aggregation; $(b)$ HCYSH-mediated endothelial injury, with consequent attenuation of $\mathrm{EDRF} / \mathrm{NO}_{\mathrm{x}}$ production, attenuates endothelial-mediated platelet inhibition and predisposes to platelet activation; $(c)$ $\mathrm{HCYSH}$ reacts with $\mathrm{NO}_{\mathrm{x}}$ under physiologic conditions to form a stable $S$-nitrosothiol ( $\mathrm{SNOHO}) ;(d)$ with oxidative metabolism of HCYSH, the potential for SNOHO formation is lost; (e) the mechanism of HCYSH-mediated endothelial injury through generation of reactive oxygen species is not supported by SNOHO; and $(f)$ SNOHO possesses intrinsic EDRF-like antiplatelet and vasodilatory properties mediated through cyclic GMP.

These data provide new insight into the mechanism of HCYSH-induced atherosclerosis and thrombosis, and highlight the larger potential of the S-NO functional group in regulation of cellular thiol biochemistry and metabolism. In proposing that $\mathrm{NO}$ availability may be of central importance to the thrombogenic and cytotoxic potential of $\mathrm{HCYSH}$, our findings may have important pharmacological implications, as well. Denitrification of organic nitrates, for example, is facilitated by thiols, including HCYSH, and $S$-nitrosothiols are proposed reaction intermediates $(51,68)$. Thus, the provision of NO equivalents may be of therapeutic value in disease states in which HCYSH plays a pathogenic role.

\section{Acknowledgments}

The authors thank Ms. Nancy Beattie for expert technical assistance. This work was supported in part by National Institutes of Health 
grants HL-40411, HL-43344, and RRO4870; by a Grant-in-Aid from the American Heart Association with funds contributed in part by the Massachusetts Affiliate; by a Merit Review Award from the Veterans Administration; and by a National Science Foundation grant CHE8814019. J. Stamler is the recipient of a Clinical Investigator Award from the National Institutes of Health (HL-02582), and J. Loscalzo is the recipient of a Research Career Development Award from the National Institutes of Health (HL-02273).

\section{References}

1. Clarke, R., L. Daly, K. Robinson, E. Naughten, S. Cahalane, B. Fowler, and I. Graham. 1991. Hyperhomocysteinemia: an independent risk factor for vascular disease. N. Engl. J. Med. 324:1149-1155.

2. Malinow, M. R. 1990. Hyperhomocyst(e)inemia: a common and easily reversible risk factor for occlusive atherosclerosis. Circulation. 81:2004-2006.

3. Malinow, M. R., G. Sexton, M. Averbuch, M. Grossman, D. Wilson, and B. Upson. 1990. Homocyst (e)inemia in daily practice: levels in coronary artery disease. Coronary Artery Disease. 1:215-220.

4. Perry, T. L. 1967. In Amino Acid Metabolism and Genetic Variation. W. L. Nyhan, editor. McGraw-Hill Inc., New York.

5. Perry, T. L., S. Hansen, L. MacDougall, P. D. Warrington. 1967. Sulfurcontaining amino acids in the plasma and urine of homocystinurics. Clin. Chim. Acta. 15:409-420.

6. Kang, S.-S., P. W. K. Wong, H. Y. Cook, M. Norusis, and J. V. Messer. 1986. Protein-bound homocyst(e)ine: a possible risk factor for coronary artery disease. J. Clin. Invest. 77:1482-1486.

7. Refsum, H., S. Helland, and P. M. Ueland. 1985. Radioenzymic determination of homocysteine in plasma and urine. Clin. Chem. 31:624-628.

8. Spindel, E., and K. S. McCully. 1974. Conversion of methionine to homocysteine thiolactone in liver. Biochim. Biophys. Acta. 343:687-691.

9. McCully, K. S. 1971. Homocysteine metabolism in scurvy, growth and arteriosclerosis. Nature (Lond.). 231:391-392.

10. James, T. N. 1990. The spectrum of diseases of the small coronary arteries and their physiologic consequences. J. Am. Coll. Cardiol. 15:763-774.

11. Harker, L. A., S. J. Slichter, C. R. Scott, and R. Ross. 1974. Homocystinemia: vascular injury and arterial thrombosis. N. Engl. J. Med. 291:537-543.

12. Harker, L. A., R. Ross, S. J. Slichter, and C. R. Scott. 1976. Homocystineinduced arteriosclerosis. The role of endothelial cell injury and platelet response in its genesis. J. Clin. Invest. 58:731-741.

13. McDonald, L., C. Bray, C. Field, F. Love, and B. Davies. 1964. Homocystinuria, thrombosis, and the blood-platelets. Lancet. i:745-746.

14. Graeber, J. E., J. H. Slott, R. E. Ulane, J. D. Schulman, and M. J. Stuart. 1982. Effect of homocysteine and homocystine on platelet and vascular arachidonic acid metabolism. Pediatr. Res. 16:490-493.

15. McCully, K. S., and A. C. A. Carvalho. 1987. Homocysteine thiolactone, N-homocysteine thiolactonyl retinamide, and platelet aggregation. Res. Commun. Chem. Pathol. Pharmacol. 56:349-360.

16. Davis, J. W., L. D. Flournoy, and P. E. Phillips. 1975. Amino acids and collagen-induced platelet aggregation. Am. J. Dis. Child. 129:1020-1021.

17. Zweifler, A. J., and R. J. Allen. 1971. An intrinsic blood platelet abnormality in a homocystinuric boy corrected by pyridoxine administration. Thromb. Diath. Haemorrh. XXVI:15-21.

18. Hilden, M., N. J. Brandt, I. M. Nilsson, and F. Schonheyder. 1974. Investigations of coagulation and fibrinolysis in homocystinuria. Acta Med. Scand. 195:533-535.

19. Thomas, G., V. A. Skrinska, and F. V. Lucas. 1986. The influence of glutathione and other thiols on human platelet aggregation. Thromb. Res. 44:859-866.

20. Stamler, J., M. Cunningham, and J. Loscalzo. 1988. Reduced thiols and the effect of intravenous nitroglycerin on platelet aggregation. Am. J. Cardiol. $62: 377-380$

21. Wall, R. T., J. M. Harlan, L. A. Harker, and G. E. Striker. 1980. Homocysteine-induced endothelial cell injury in vitro: a model for the study of vascular injury. Thromb. Res. 18:113-121.

22. Starkebaum, G., and J. M. Harlan. 1986. Endothelial cell injury due to copper-catalyzed hydrogen peroxide generation from homocysteine. J. Clin. Invest. 77:1370-1376.

23. de Groot, P. G., C. Willems, G. H. J. Boers, M. D. Gonsalves, W. G. van Aken, and J. A. van Mourik. 1983. Endothelial cell dysfunction in homocystinuria. Eur. J. Clin. Invest. 13:405-410.

24. McCully, K. S., and B. D. Ragsdale. 1970. Production of arteriosclerosis by homocysteinemia. Am. J. Pathol. 61:1-8.

25. McCully, K. S., and R. B. Wilson. 1975. Homocysteine theory of arteriosclerosis. Atherosclerosis. 22:215-227.

26. Palmer, R. M. J., A. G. Ferrige, and S. Moncada. 1987. Nitric oxide release accounts for the biological activity of endothelium-derived relaxing factor Nature (Lond.). 327:524-526.

27. Ignarro, L. J., G. M. Buga, K. S. Wood, R. E. Byrns, and G. Chaudhuri. 1987. Endothelium-derived relaxing factor produced and released from artery and vein is nitric oxide. Proc. Natl. Acad. Sci. USA. 84:9265-9269.

28. Myers, P. R., R. L. Minor, Jr., R. Guerra, Jr., H. Bates, and D. G. Harrison. 1990. Vasorelaxant properties of the endothelium-derived relaxing factor more closely resemble S-nitrosocysteine than nitric oxide. Nature (Lond.). 345:161-163.

29. Wei, E. P., and H. Kontos. 1990. Hydrogen peroxide and endotheliumdependent arteriolar dilation. Implications for the identification of endotheliumderived relaxing factor generated by acetycholine. Hypertension (Dallas). 16:162-169.

30. Oae, S., and K. Shinhama. 1983. Organic thionitrites and related substances. A review. Org. Prep. Proc. 15:165-169.

31. Stamler, J. S., D. I. Simon, J. A. Osborne, M. E. Mullins, O. Jaraki, T. Michel, D. J. Singel, and J. Loscalzo. 1992. S-nitrosylation of proteins with nitric oxide: synthesis and characterization of biologically active compounds. Proc. Natl. Acad. Sci. USA. 89:444-448.

32. Schwartz, S. W. 1978. Selection and characterization of bovine aortic endothelial cells. In Vitro (Rockville). 14:966-980.

33. Davies, P. F., G. A. Truskey, H. B. Warren, S. E. O'Connor, and B. H. Eisenhaure. 1985. Metabolic cooperation between vascular endothelial cells and smooth muscle cells in co-culture: changes in low density lipoprotein metabolism. J. Cell. Biol. 101:871-879.

34. Stamler, J. S., M. E. Mendelsohn, P. Amarante, D. Smick, N. Andon, P. F Davies, J. P. Cooke, and J. Loscalzo. 1989. N-acetylcysteine potentiates platelet inhibition by endothelium-derived relaxing factor. Circ. Res. 65:789-795.

35. Cooke, J. P., J. S. Stamler, N. Andon, P. F. Davies, and J. Loscalzo. 1989 Flow stimulates endothelial cells to release a nitrovasodilator that is potentiated by reduced thiol. Am. J. Physiol. 28:H804-H812.

36. Phillips, P. G., and M.-F. Tsan. 1988. Direct staining and visualization of endothelial monolayers cultured on synthetic polycarbonate filters. J. Histochem. Cytochem. 36:551-554.

37. Hawiger, J., S. Parkinson, and S. Timmons. 1980. Prostacyclin inhibits mobilization of fibrinogen-binding sites on human ADP- and thrombin-treated platelets. Nature (Lond.). 2831:195-198.

38. Born, G. V., and M. J. Cross. 1963. The aggregation of blood platelets. $J$. Physiol. (Lond.) 168:178-195.

39. Osborne, J. A., P. H. Lento, M. R. Siegfried, G. L. Stahl, B. Fusman, and A. M. Lefer. 1989. Cardiovascular effects of acute hypercholesterolemia in rabbits. Reversal with lovastatin treatment. J. Clin. Invest. 83:465-473.

40. Sedlak, J., and R. H. Lindsay. 1968. Estimation of total protein -bound and nonprotein-bound sulfhydryl groups in tissue with Ellman's reagent. Anal. Biochem. 25:195-205.

41. Root, R. K., J. Metcalf, N. Oshino, and B. Chance. 1975. $\mathrm{H}_{2} \mathrm{O}_{2}$ release from human granulocytes during phagocytosis. I. Documentation, quantitation, and some regulating factors. J. Clin. Invest. 53:945-955.

42. Saville, B. 1958. A scheme for the colorimetric determination of microgram amounts of thiols. Analyst. 83:670-672.

43. Bonnett, R., R. Hollyhead, B. L. Johnson, and E. W. Randall. 1975. Reaction of acidified nitrite solutions with peptide derivatives: evidence for nitrosamine and thionitrite formation from ${ }^{15} \mathrm{~N}$ NMR studies. J. Chem. Soc. Perkin Trans. I. 2261-2264.

44. Stamler, J. S., O. Jaraki, J. A. Osborne, D. I. Simon, J. Keaney, J. Vita, D. Singel, C. R. Valeri, and J. Loscalzo. 1992. Nitric oxide circulates in mammalian plasma primarily as an S-nitroso adduct of serum albumin. Proc. Natl. Acad. Sci. USA. 89:7674-7677.

45. Stamler, J. S., and J. Loscalzo. 1992. Capillary zone electrophoretic detection of biologic thiols and their S-nitrosated derivatives. Anal. Chem. 64:779785.

46. Kowaluk, E. A., and H.-L. Fung. 1990. Spontaneous liberation of nitric oxide cannot account for in vitro vascular relaxation by S-nitrosothiols. J. Pharmacol. Exp. Ther. 256:1256-1264.

47. Aldred, S. E., and D. L. H. Williams. 1987. Kinetics and mechanism of the nitrosation of alcohols, carbohydrates and a thiol. J. Chem. Soc. Perkin Trans. II. 777-782.

48. Byler, D. M., D. K. Grosser, and H. Susi. 1983. Spectroscopic estimation of the extent of S-nitrosothiol formation by nitrite action on sulfhydryl groups. $J$. Agric. Food. Chem. 31:523-527.

49. Riegel, B., and V. DuVigneaud. 1935. The isolation of homocysteine and its conversion to a thiolactone. J. Biol. Chem. 112:149-154.

50. Ignarro, L. J., J. C. Edwards, D. Y. Gruetter, B. K. Barry, and C. A. Gruetter. 1980. Possible involvement of S-nitrosothiols in the activation of guantlate cyclase by nitroso-compounds. FEBS (Fed. Eur. Biochem. Soc.) Lett. 110:275-278.

51. Zucker, M. B., and N. C. Masiello. 1984. Platelet aggregation caused by dithiothreitol. Thromb. Haemostasis. 51:119-124. 
52. Hofman, J., W. Losche, B. Hofman, P. Arese, A. Bosia, G. Pescarmona, and U. Till. 1983. Effects of compounds causing reversible pertubation of the cellular thiol disulfide status on the aggregation of human platelets. Biomed. Biochim. Acta. 42:479-487.

53. Ignarro, L. J. 1989. Biological actions and properties of endothelium-derived nitric oxide formed and released from artery and vein. Circ. Res. 65:1-21.

54. Schimke, R. N., V. A. McKusick, T. Hwang, and A. D. Pollack. 1965. Homocystinuria. Studies of 20 families with 38 affected members. JAMA (J. Am. Med. Assoc.). 193:711.

55. Hill-Zobel, R. L., R. E. Pyeritz, U. Scheffel, O. Malpica, S. Engin, E. E Camarge, M. Abbott, T. R. Guilarte, J. Hill, P. A. McIntyre, et al. 1982. Kinetics and distribution of ${ }^{111}$ Indium-labeled platelets in patients with homocystinuria. N. Engl. J. Med. 307:781-786.

56. Uhleman, E. R., J. H. TenPas, A. W. Lucky, J. D. Schulman, S. H. Mudd and N. R. Schulman. 1982. Platelet survival and morphology in homocystinuria due to cystathionine synthase deficiency. N. Engl. J. Med. 307:781-786.

57. Rodgers, G. M., and M. T. Conn. 1990. Homocysteine, an atherogenic stimulus reduces protein $\mathrm{C}$ activation by arterial and venous endothelial cells. Blood. 75:895-901.

58. Jocelyn, P. C. 1972. In Biochemistry of the SH Group. Academic Press Ltd., London. pp. 39 and 253.

59. Randon, J., T. Lecompte, M. Chignard, W. Siess, G. Marlas, F. Dray, and B. B. Vargaftig. 1981. Dissociation of platelet activation from transmethylation of their membrane phospholipids. Nature (Lond.). 293:660-662.

60. Akbar, H., and K. Romstedt. 1984. 3-Deazoadenosine and L-homocys- teine inhibit human platelet activation induced by arachidonic acid, U46619 and phospholipase C. Thromb. Res. 36:369-376.

61. Eger, W. 1957. Die Bedeutung der sulfhydryl-amino and carboxyl-gruppen Kurzkettiger Kohlenstoffverbindungen fur ihre nekrotrope Leberschitzwitkung. Arzneim. Forsch. 7:601-606.

62. Rodgers, G. M., and W. H. Kane. 1986. Activation of endogenous factor $\mathrm{V}$ by a homocysteine-induced vascular endothelial cell activator. J. Clin. Invest. 77:1909-1916.

63. Gaggi, R., and A. M. Gianni. 1973. The role of homocysteine in the pathogenesis of atherosclerosis. Arzneim. Forsch. 2:287-297.

64. Mollace, V., D. Salvenini, W. C. Sessa, and J. R. Vane 1991. Inhibition of human platelet aggregation by endothelium-derived relaxing factor, sodium nitroprusside or iloprost is potentiated by captopril and reduced thiols. J. Pharmacol. Exp. Ther. 258:820-823.

65. Nishiuch, Y., M. Sasaki, M. Nakayasu, and A. Oikawa. 1976. Cytotoxicity of cysteine in culture media. In Vitro. 12:635-638.

66. Parthasarathy, S. 1987. Oxidation of low-density lipoprotein by thiol compounds leads to its recognition by the acetyl LDL receptor. Biochim. Biophys. Acta. 917:337-340.

67. Heinecke, J. W., H. Rosen, L. A. Suzuki, and A. Chait. 1987. The role of sulfur-containing amino acids in superoxide production and modification of low density lipoprotein by arterial smooth muscle cells. J. Biol. Chem. 262:1009810103.

68. Feelisch, M., and E. A. Novack. 1987. Correlation between nitric oxide formation during degradation of organic nitrates and activation of guanylate cyclase. Eur. J. Pharm. 139:19-30. 